Efficacy of Intensive Physiotherapy in Combination with Low-dose Etanercept in Active Spondyloarthritis:

\section{A Monocentric Pilot Study}

To the Editor:

The introduction of tumor necrosis factor- $\alpha$ inhibitors (TNFi) in the treatment of spondyloarthritis was a landmark ${ }^{1,2}$, but ongoing research in health economics still questions the cost-effectiveness of this therapy ${ }^{3}$. In contrast, nonpharmacological measures, such as physical therapy, appear to be more economical in this setting and have also shown a positive effect on the Bath Ankylosing Spondylitis Disease Activity Index (BASDAI) and the Bath Ankylosing Spondylitis Functionality Index (BASFI), as well as on pain and mobility ${ }^{4}$. Although the idea of combining these 2 treatment modalities is attractive, there is still a lack of high-quality studies that examine the effects of physical therapy in combination with drugs such as $\mathrm{TNFi}$, particularly in everyday clinical settings ${ }^{5,6}$.

To address this idea, we performed a proof-of-concept study, in which the dose of the TNFi etanercept (ETN) was 50\% of the standard dose for adult patients (i.e., $25 \mathrm{mg} /$ week subcutaneously) and combined with standard intensive physiotherapy ( 3 sessions of $30 \mathrm{~min} /$ week; 8 patients were treated at the Kerckhoff-Klinik and 12 at participating physiotherapy practices; information about the procedures is to be found in the Supplementary Data, available online at jrheum.org) over 4 months in patients with active spondyloarthritis (BASDAI > 4). Thereafter, the patients were followed for another 2 months while still receiving low-dose ETN. Afterward, patients were asked whether to continue with regular or reduced doses of ETN. The local ethics committee of the University of Gießen approved the study and 20 patients were eligible and gave informed consent during a recruitment period of 10 months (patient characteristics are shown in Table 1). Because of side effects, 2 patients dropped out (1 had extensive injection reactions and 1 developed a rash). Another patient did not respond to therapy and discontinued treatment after 3 months (all patients were included in the statistical analysis). Of note, 2 patients received TNFi therapy previous to study start, but agreed to the recommended washout period for clinical trials [4 weeks for ETN $(n=1)$ and 8 weeks for infliximab $(n=1)]$. None of the other participants received TNFi therapy prior to the study $(\mathrm{n}=18)$.

The results showed a decrease of BASDAI from 6.0 [median; interquartile range (IQR) 5.1-6.7] to 3.9 (IQR 2.4-4.8; p < 0.0001) after 8

Table 1. Patient characteristics. BASDAI inflammation refers to the mean of BASDAI questions 5 and 6.

\begin{tabular}{lc}
\hline Baseline Characteristics & Total, $\mathrm{n}=20$ \\
\hline Age, yrs, mean \pm SD & $46.2 \pm 7.3$ \\
Male, $\mathrm{n}(\%)$ & $15(75)$ \\
DMARD use at baseline, $\mathrm{n}(\%)$ & $6(30)$ \\
NSAID use at baseline, $\mathrm{n}(\%)$ & $16(80)$ \\
Previous TNFi therapy, $\mathrm{n}(\%)$ & $2(10)$ \\
HLA-B27 positive, $\mathrm{n}(\%)$ & $14(70)$ \\
Psoriasis, $\mathrm{n}(\%)$ & $4(20)$ \\
BASDAI, median (IQR) & $6.0(5.1-6.7)$ \\
BASDAI-inflammation, median (IQR) & $5.4(4.3-6.4)$ \\
BASFI, median (IQR) & $5.3(4.0-7.0)$ \\
Pain (VAS), median (IQR) & $6.3(6.0-7.8)$ \\
BASMI, median (IQR) & $2.5(1.0-5.0)$ \\
\hline
\end{tabular}

DMARD: disease-modifying antirheumatic drug; NSAID: nonsteroidal antiinflammatory drug; TNFi: tumor necrosis factor- $\alpha$ inhibitor; BASDAI: Bath Ankylosing Spondylitis Disease Activity Index; IQR: interquartile range; BASFI: Bath Ankylosing Spondylitis Functionality Index; VAS: visual analog scale; BASMI: Bath Ankylosing Spondylitis Metrology Index. weeks and to 3.2 (IQR 2.0-5.0; p < 0.0001) after 16 weeks (Figure 1). After discontinuation of intensive physiotherapy, disease activity remained at a low level for another 2 months (BASDAI median 3.6; IQR 1.5-4.9; 4 vs 6 months, $\mathrm{p}=0.84)$. The same results were observed for the functionality index (BASFI; Figure 1). There was no difference in BASDAI response comparing patients who received physiotherapy at the hospital or at participating physiotherapy practices (Figure 1). With respect to response rates ${ }^{7}$, patients benefitted most after 4 months of combination therapy. At 6 months, a slight trend toward worsening developed for the Assessment of SpondyloArthritis International Society response rate of $40 \%$ (ASAS40) and the BASDAI50 (50\% improvement of the baseline BASDAI score), but not for ASAS20 response rates. Most interestingly, a pronounced reduction in nonsteroidal antiinflammatory drug (NSAID) use could be recorded; patients were allowed to take them on an on-demand basis (Supplementary Data, available online at jrheum.org). At baseline, 16 patients were taking NSAID regularly compared to only 8 patients at the end of the study. Moreover, half of the patients decided to continue on low-dose ETN after the study period. Of note, using a simplified calculation by considering prices of the German market, the total savings of the combination therapy compared to full-dose ETN therapy would have been about $76,000 €$ for all patients during the study (Supplementary Data, available online at jrheum.org).

Although lacking a control group, the results of our study provide strong evidence that intensive physiotherapy could substitute for a reduction of dosage of TNFi such as ETN and become a therapeutic alternative, especially in the context of cost-effectiveness.

\section{ACKNOWLEDGMENT}

We thank our colleagues Kai Fischer and Stanislav Nesterov. F.M.P. Meier received a grant from Pfizer for an investigator-initiated research project and speaker fees from Pfizer. U. Müller-Ladner received speaker fees from Pfizer. U. Lange received speaker fees from Pfizer.

\section{ONLINE SUPPLEMENT}

Supplementary data for this article are available online at jrheum.org.

FLORIAN M.P. MEIER, MD, Resident; ULF MÜLLER-LADNER, MD, Professor of Medicine and Director of the Department of Rheumatology and Clinical Immunology; UWE LANGE, MD, Professor of Medicine and Assistant Medical Director of the Department of Rheumatology and Clinical Immunology, Justus-Liebig-University Giessen, Kerckhoff Clinic Bad Nauheim, Germany. Address correspondence to Professor Uwe Lange, Department of Internal Medicine and Rheumatology, Justus-Liebig-University Giessen, Kerckhoff Clinic Bad Nauheim, Benekestr. 2-8, Bad Nauheim 61231, Germany.

E-mail: u.lange@kerckhoff-klinik.de

\section{REFERENCES}

1. Braun J, van den Berg R, Baraliakos X, Boehm H, Burgos-Vargas R, Collantes-Estevez E, et al. 2010 update of the ASAS/EULAR recommendations for the management of ankylosing spondylitis. Ann Rheum Dis 2011;70:896-904.

2. Gossec L, Smolen JS, Gaujoux-Viala C, Ash Z, Marzo-Ortega H, van der Heijde D, et al. European League Against Rheumatism recommendations for the management of psoriatic arthritis with pharmacological therapies. Ann Rheum Dis 2012;71:4-12.

3. Kirchhoff TD, Mittendorf T, Schmidt RE, Jablonka A, Merkesdal S. Cost-effectiveness of TNF- $\alpha$ inhibition in active ankylosing spondylitis: a systematic appraisal of the literature. Expert Rev Pharmacoecon Outcomes Res 2012;12:307-17.

4. van den Berg R, Baraliakos X, Braun J, van der Heijde D. First update of the current evidence for the management of ankylosing spondylitis with non-pharmacological treatment and non-biologic drugs: a systematic literature review for the ASAS/EULAR management recommendations in ankylosing spondylitis. 

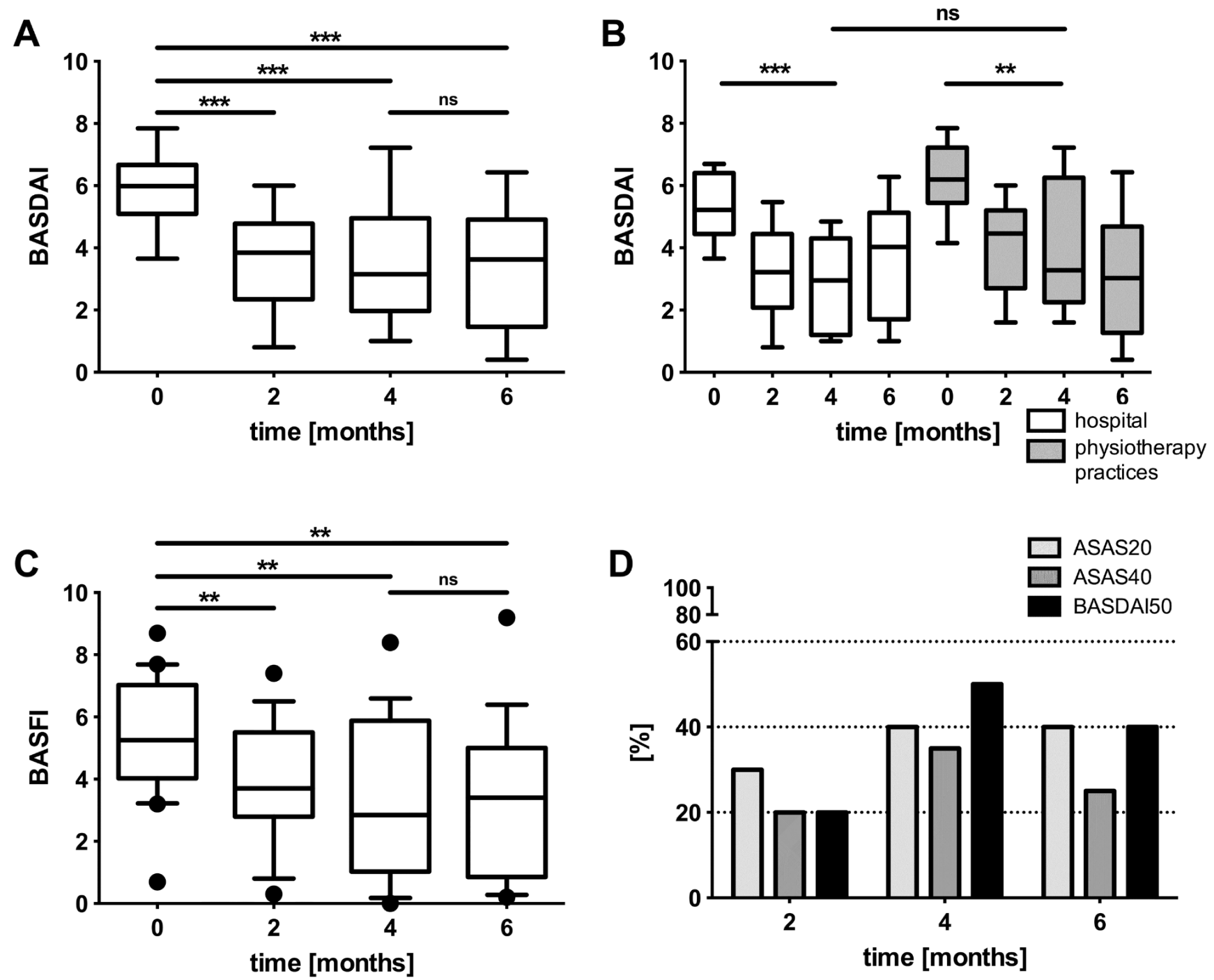

Figure 1. Activity and functionality scores and response rates. A. Box plot diagram of the BASDAI scores (whiskers indicating min-max) of baseline and after 2, 4, and 6 months of therapy. B. Box plot diagram of the BASDAI scores (whiskers indicating min-max) of baseline and after 2, 4, and 6 months of therapy; separated for patients treated at the hospital or at cooperating practices. C. Box plot diagram of the BASFI scores (whiskers indicating 10-90 percentile) of baseline and after 2, 4, and 6 months of therapy. D. Column diagram of the respective response rates for ankylosing spondylitis. ** $\mathrm{p}<0.01$; *** $\mathrm{p}<0.001$. BASDAI: Bath Ankylosing Spondylitis Disease Activity Index; BASFI: Bath Ankylosing Spondylitis Functionality Index; ASAS: Assessment of SpondyloArthritis International Society; ns: not significant.

Rheumatology 2012;51:1388-96.

5. Dagfinrud H, Kvien TK, Hagen KB. Physiotherapy interventions for ankylosing spondylitis. Cochrane Database Syst Rev 2008:CD002822.

6. Dagfinrud H, Halvorsen S, Vøllestad NK, Niedermann K, Kvien TK, Hagen KB. Exercise programs in trials for patients with ankylosing spondylitis: do they really have the potential for effectiveness? Arthritis Care Res 2011;63:597-603.
7. Sieper J, Rudwaleit M, Baraliakos X, Brandt J, Braun J, Burgos-Vargas R, et al. The Assessment of SpondyloArthritis international Society (ASAS) handbook: a guide to assess spondyloarthritis. Ann Rheum Dis 2009;68 Suppl 2:ii1-44.

J Rheumatol 2014;41:9; doi:10.3899/jrheum.131431 